\title{
Age- and sex-related differences in pituitary height and its effect on the optic chiasm height
}

\author{
Sebahattin Sari · Salih Hamcan · Bilal Battal • \\ Veysel Akgun · Serhat Celikkanat
}

Received: 19 November 2014/ Accepted: 15 December 2014/Published online: 20 December 2014

(C) Springer-Verlag France 2014

We read the recent article titled "Topographic variations of the optic chiasm and the pituitary stalk: a morphometric study based on midsagittal T2-weighted MR images" by Long et al. [1] published in Surgical and Radiologic Anatomy (doi:10.1007/s00276-014-1265-y) with great interest. The authors evaluated topographic variations of optic chiasm and pituitary stalk in situ based on midsagittal T2-weighted MR images. We would like to make a contribution regarding age- and sex-related differences in pituitary height and its effect on the optic chiasm height.

Long et al. [1] reported that the height of the optic chiasm was defined and measured as the shortest distance between the inferior margin of the optic chiasm and the upper surface of the pituitary gland. The authors separated the cases into 157 (32.7\%) children (under the age of 18) and $323(67.3 \%)$ adults (18 years of age or above). But, we know that the height of the normal pituitary gland is bigger in newborns than in infants. It is also bigger in women than in men. The normal highest values for the height of pituitary gland in a population younger than 12 years old, adult men and adult women are 6,8 and $9 \mathrm{~mm}$, respectively. Nevertheless, the normal values for pubertal girls and peripartum women are 10 and $12 \mathrm{~mm}$, respectively. The upper border of the pituitary gland may show convexity in the peripartum and pubertal period [2].The variations in the height of the pituitary gland due to various physiologic reasons might have affected the measurement of the height of the optic chiasm in different age and gender groups. We thought that if the height of the optic chiasm was measured from the level of the anterior skull base plane instead of the upper surface of the pituitary gland, the authors would obtain more accurate results without the effect of these physiologic differences. The authors evaluated cases younger than 18 years old classified into only one group as children. However, the first 18 years of life contains newborn, pre-pubertal, pubertal (10-15 years old) and post-pubertal periods (15-18 years old). Since these periods are related with the physiologic pituitary volume changes, the data obtained from the children (under age 18 years) may not be homogenous. In other words, the height of the chiasm measured based on the upper surface of the pituitary gland may show fluctuation even in exactly the same case within the first 18 years of life. A similar situation should also be considered in peripartum women.

Conflict of interest The authors declare that they have no conflict of interest.

\section{References}

1. Long H, Qi ST, Song Y, Pan J, Zhang XA, Yang KJ (2014) Topographic variations of the optic chiasm and the pituitary stalk: a morphometric study based on midsagittal T2-weighted MR images. Surg Radiol Anat 36:775-781

2. Sari S, Sari E, Akgun V, Ozcan E, Ince S, Saldir M, Babacan O, Acikel C, Basbozkurt G, Ozenc S, Yesilkaya S, Kilic C, Kara K, Vurucu S, Kocaoglu M, Yesilkaya E (2014) Measures of pituitary gland and stalk: from neonate to adolescence. J Pediatr Endocrinol Metab 27:1071-1076 